\title{
Efficacy and safety of biosimilar CT-P17 versus reference adalimumab in subjects with rheumatoid arthritis: 24-week results from a randomized study
}

Jonathan Kay ${ }^{1}$, Janusz Jaworski ${ }^{2}$, Rafal Wojciechowski ${ }^{3}$, Piotr Wiland ${ }^{4}$, Anna Dudek$^{5}$, Marek Krogulec ${ }^{6}$,

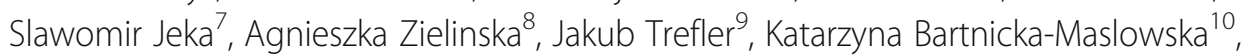
Magdalena Krajewska-Wlodarczyk ${ }^{11}$, Piotr A. Klimiuk ${ }^{12}$, Sang Joon Lee ${ }^{13}$, Yun Ju Bae ${ }^{13}$, Go Eun Yang ${ }^{13}$, Jae Kyoung Yoo ${ }^{13}$, Daniel E. Furst ${ }^{14,15,16+}$ and Edward Keystone ${ }^{17^{*+}}$

\begin{abstract}
Background: To demonstrate equivalent efficacy of the proposed high-concentration (100 mg/ml), citrate-free adalimumab biosimilar CT-P17 to European Union-approved adalimumab (EU-adalimumab) in subjects with active rheumatoid arthritis (RA).

Methods: This randomized, double-blind phase III study (ClinicalTrials.gov, NCT03789292) randomized (1:1) subjects with active RA at 52 centers to receive CT-P17 or EU-adalimumab $40 \mathrm{mg}$ subcutaneously every 2 weeks until week 52. Results to week 24 are reported here. The primary endpoint was $20 \%$ improvement by American College of Rheumatology criteria (ACR20) response rate at week 24. Equivalence was concluded if the corresponding confidence intervals (Cls) for the estimate of treatment difference were within predefined equivalence margins: -15 to $15 \%$ (95\% Cl; European Medicines Agency assumption); - 12 to 15\% (90\% Cl; Food and Drug Administration assumption). Additional efficacy, pharmacokinetic, usability, safety, and immunogenicity endpoints were evaluated.

Results: 648 subjects were randomized (324 CT-P17; 324 EU-adalimumab). The ACR20 response rate at week 24 was $82.7 \%$ ( $n=268 / 324)$ in both groups (intention-to-treat population). The $95 \% \mathrm{Cl}$ ( -5.94 to 5.94 ) and $90 \% \mathrm{Cl}(-4.98$ to 4.98$)$ were within predefined equivalence margins for both assumptions and equivalent efficacy was concluded. Additional endpoints and overall safety were comparable between groups. Mean trough serum concentrations of CT-P17 were slightly higher than those of EU-adalimumab. Immunogenicity was slightly lower numerically for the CT-P17 group than for the EU-adalimumab group.
\end{abstract}

(Continued on next page)

\footnotetext{
* Correspondence: edkeystone@rheumkey.com

The manuscript has not been previously published and the manuscript is not under consideration elsewhere. Selected results from this study were presented in a poster at the American College of Rheumatology (ACR) Convergence 2020.

${ }^{\dagger}$ Daniel E. Furst and Edward Keystone are co-senior authors.

${ }^{17}$ University of Toronto, Toronto, Canada

Full list of author information is available at the end of the article
} changes were made. The images or other third party material in this article are included in the article's Creative Commons licence, unless indicated otherwise in a credit line to the material. If material is not included in the article's Creative Commons licence and your intended use is not permitted by statutory regulation or exceeds the permitted use, you will need to obtain permission directly from the copyright holder. To view a copy of this licence, visit http://creativecommons.org/licenses/by/4.0/ The Creative Commons Public Domain Dedication waiver (http://creativecommons.org/publicdomain/zero/1.0/) applies to the data made available in this article, unless otherwise stated in a credit line to the data. 
(Continued from previous page)

Conclusions: CT-P17 and EU-adalimumab have equivalent efficacy and comparable safety and immunogenicity in subjects with active RA. Overall safety of CT-P17 is consistent with the known safety profile of reference adalimumab.

Trial registration: ClinicalTrials.gov, NCT03789292. Registered 28 December 2018-retrospectively registered.

Keywords: Adalimumab, Biologics, Biosimilars, Comparative effectiveness, Immunogenicity, Monoclonal antibodies, Rheumatoid arthritis, Safety, Tumor necrosis factor inhibitors

\section{Background}

Biological disease-modifying antirheumatic drugs (bDMARDs), such as tumor necrosis factor (TNF) inhibitors, are recommended for the treatment of rheumatoid arthritis (RA) when disease activity remains moderate or high despite conventional synthetic DMARD (csDMARD) monotherapy [1]. Adalimumab is an antiTNF monoclonal antibody that effectively treats RA [25]. Biosimilars are highly similar to their reference products in terms of quality characteristics, biological activity, safety, and efficacy [6]. Since 2016, several adalimumab biosimilars have been licensed by the US Food and Drug Administration (FDA) and the European Medicines Agency (EMA) [7, 8]. European League Against Rheumatism (EULAR) recommendations for the treatment of RA position biosimilar DMARDs (bsDMARDs) equivalently to their reference products in treatment algorithms, and suggest that lower-priced biosimilars are preferred for their potential to reduce healthcare expenditures [9].

CT-P17 is in development as a proposed adalimumab biosimilar [10, 11]. CT-P17 is administered at $100 \mathrm{mg} / \mathrm{ml}$, reflecting the high-concentration formulation of reference adalimumab [12-14], and is also citrate-free, which could reduce discomfort during injection $[12,15]$. To date, CTP17 has been evaluated in two randomized phase I studies evaluating the pharmacokinetics (PK) and safety of CTP17 in healthy adults: a double-blind study comparing CT-P17 to European Union-approved adalimumab (EUadalimumab) and US-licensed adalimumab (ClinicalTrials. gov NCT03970824) [11] and an open-label study comparing CT-P17 administration via autoinjector or prefilled syringe (ClinicalTrials.gov NCT04295356) [16].

This randomized, active-controlled, double-blind, multicenter, phase III study was designed to demonstrate that the efficacy of CT-P17 at week 24 is equivalent to that of EU-adalimumab. The study also evaluated PK, usability, and overall safety, including immunogenicity.

\section{Methods}

\section{Study design and procedures}

This randomized, double-blind, active-controlled, multicenter, phase III study was conducted at 52 centers in six countries (Bulgaria, Hungary, Lithuania, Peru,
Poland, Ukraine; see Supplementary Table 1, Additional file 1). There were three study periods: screening (days - 42 to -1 ), treatment (weeks 0-48), and end-ofstudy (week 52). Before dosing at week 0 , subjects were randomized (1:1) to receive treatment with $40 \mathrm{mg}$ (100 $\mathrm{mg} / \mathrm{ml}$ ) of either CT-P17 or EU-adalimumab (Humira, AbbVie Deutschland GmbH Co. KG, Ludwigshafen, Germany) every 2 weeks (q2w) until week 24 (treatment period 1). Before dosing at week 26, subjects in the EUadalimumab group were randomized (1:1) either to continue EU-adalimumab or to switch to CT-P17 (both q2w until week 48) (treatment period 2). Subjects receiving CT-P17 during treatment period 1 continued to receive CT-P17 in treatment period 2. Results up to week 24 are reported here.

CT-P17 and EU-adalimumab were administered by subcutaneous injection via prefilled syringe. After training in proper injection technique, subjects (or caregivers, as needed) could self-administer injections at home, unless injection at the study center was required for usability assessment. Subjects also received treatment with methotrexate (MTX; 12.5-25 mg/week, or $10 \mathrm{mg} /$ week if intolerant to a higher dose, oral or parenteral [intramuscular or subcutaneous] dose) and folic acid ( $\geq 5 \mathrm{mg} /$ week, oral).

Randomization was conducted using an interactive web response system (IWRS). The biostatistics team used Rave Randomization and Trial Supply Management (Medidata Solutions, New York) to generate the randomization schedule for the IWRS, which linked sequential subject randomization numbers to treatment codes. Randomization was by permuted block (block size remains blinded until final database lock) and was stratified by country and Simplified Disease Activity Index (SDAI) at screening (>26 vs $\leq 26)$. As prespecified in the protocol, the study was unblinded for reporting purposes after the database lock for data up to week 24. Efficacy, PK, usability, immunogenicity, and safety endpoints were evaluated by separate, predefined unblinded teams constituted by the sponsor and by the Contract Research Organization (CRO). The investigators, subjects, and other teams in the CRO and the sponsor will remain blinded until the end of the study. 
The study was performed in accordance with the Declaration of Helsinki [17] and Good Clinical Practice guidelines [18]. All national, state, and local laws or regulations were followed. Before study initiation, the study protocol was reviewed and approved by the independent ethics committee/institutional review board at each site (see Supplementary Table 1, Additional file 1). All subjects provided written informed consent. The study was registered with ClinicalTrials.gov (NCT03789292).

\section{Subjects}

Full eligibility criteria are detailed in Additional file 1. Subjects ranged between 18 and 75 years of age, were diagnosed with RA according to the 2010 American College of Rheumatology (ACR)/EULAR classification criteria [19], and had active disease, defined by the presence of $\geq 6$ swollen joints (of 66 assessed), $\geq 6$ tender joints (of 68 assessed), and either erythrocyte sedimentation rate $(\mathrm{ESR})>28 \mathrm{~mm} /$ hour or serum C-reactive protein (CRP) concentration $>1.0 \mathrm{mg} / \mathrm{dl} \quad(>10 \mathrm{mg} / \mathrm{l})$ at screening. Subjects had received oral or parenteral MTX at a dose of $12.5-25 \mathrm{mg} /$ week, or $10 \mathrm{mg}$ /week if intolerant to a higher dose, for $\geq 12$ weeks, and had been on a stable dose and route of administration of MTX for $\geq 4$ weeks before the first administration of study drug (day 1). Key exclusion criteria included prior bDMARD or targeted synthetic DMARD treatment for RA or prior TNF inhibitor treatment for any diagnosis; active or latent tuberculosis, or history of tuberculosis; or history of or current serious infection.

\section{Study endpoints}

The primary efficacy endpoint was the proportion of subjects achieving clinical response according to 20\% improvement by ACR response criteria (ACR20) at week 24. Secondary efficacy endpoints up to week 24 were ACR20, ACR50, and ACR70 response, hybrid ACR response, Disease Activity Score in 28 joints (DAS28)-CRP response, EULAR (CRP) response, SDAI and Clinical Disease Activity Index (CDAI) remission rate, and 36item Short Form Health Survey (SF-36) physical and mental component scores. DAS28-CRP and Boolean remission rates were analyzed post hoc. Trough serum adalimumab concentration $\left(C_{\text {trough }}\right)$ was evaluated as a secondary PK endpoint. Usability evaluations (Bulgaria and Poland only) included subject-reported outcomes from the Self-Injection Assessment Questionnaire (SIAQ) administered before (PRE-SIAQ) and after (POST-SIAQ) self-injection, and successful self-injection as determined by Self-Injection Assessment Checklist completed by study center staff. Safety was evaluated throughout; immunogenicity and local site pain were also assessed.

\section{Study assessments}

Study assessments and time points for evaluation are specified in Supplementary Table 2 (Additional file 1). For efficacy assessments, procedures were performed at the study center before study drug administration. A blinded independent joint assessor was assigned at each study center. Blood samples for PK analysis were obtained predose (immediately before study drug injection) for all PK sampling time points. Usability assessments were conducted at weeks $4,6,8$, and 24 . Safety assessments performed throughout included treatmentemergent adverse events (TEAEs), TEAEs of special interest (TEAESI), immunogenicity, clinical monitoring for tuberculosis, and review of prior and concomitant medications. TEAEs were recorded according to the Common Terminology Criteria for Adverse Events v5.0 and were coded to System Organ Class (SOC) and Preferred Term according to the Medical Dictionary for Regulatory Affairs v22.0. Prior and concomitant medications were coded using the World Health Organization Drug Dictionary (March 2019 version). Protocolspecified TEAESIs were injection-site reactions (ISRs), hypersensitivity/allergic reactions, infections, and malignancies. Local site pain was assessed by using a $100-\mathrm{mm}$ visual analog scale (VAS) at all study visits (except weeks 12 and 20).

Immunogenicity was evaluated at all study visits. Antidrug antibodies (ADAs) were detected using a validated electrochemiluminescent bridging assay with acid dissociation. ADA-positive samples underwent further analysis to confirm the specificity of binding and to quantify ADA titer. If a sample was confirmed positive for specific ADAs, the presence of neutralizing antibodies (NAbs) was investigated. A validated electrochemiluminescent assay with affinity capture elution was used to measure neutralizing activity against adalimumab in human serum.

\section{Statistical analyses}

A sample size of 450 subjects (225 per treatment group) was determined to provide $\geq 80 \%$ statistical power to demonstrate equivalence of ACR20 response at week 24, using nQuery Adviser (v7.0; nQuery, Boston, MA). This calculation was based on two sets of statistical assumptions to meet the different requirements of regulatory authorities in the European Union and the USA: an equivalence margin of -15 to $15 \%$ using a 21 -sided $2.5 \%$ significance level of an equivalence test (predefined in the protocol; EMA assumption), and an asymmetric equivalence margin of -12 to $15 \%$ using a 21 -sided $5 \%$ significance level of an equivalence test (FDA assumption). To allow for a possible dropout rate of $20 \%$, the target sample size was 564 subjects (282 per treatment group). 
Analysis populations are described in Additional file 1. The intention-to-treat (ITT) population included all subjects enrolled and randomized to receive a dose of either study drug, regardless of whether study drug dosing was completed. The ITT population was the primary analysis population for the primary endpoint, which was also assessed in the per-protocol (PP) population as a supportive analysis. The analysis was conducted by the exact binomial approach using a Farrington-Manning score method (inverting 21 -sided test) [20]. A sensitivity analysis for the primary efficacy endpoint was performed in both the ITT and the PP populations using logistic regression with treatment group as a fixed effect and country and disease activity by SDAI at screening as covariates. Selected analyses were also conducted by ADA status. Post hoc analyses were conducted to compare parameters between treatment groups (Tables 1, 2, and 3 ), with $p$ values generated by the Wald test (for proportional values) or $t$ test (for mean values). All statistical analyses were performed using SAS software v9.4 (SAS Institute, Cary, $\mathrm{NC}$ ).

\section{Results}

\section{Subject disposition and baseline characteristics}

Subjects were recruited between December 5, 2018, and April 25, 2019 (last subject week 24 visit: October 8, 2019). Of the 648 subjects who were randomized, 324 to each of the CT-P17 and EU-adalimumab groups (Fig. 1), $612(94.4 \%)$ completed study treatment up to week 24 (CT-P17, 305/324 [94.1\%]; EU-adalimumab, 307/324 [94.8\%]). Nineteen (5.9\%) and 17 (5.2\%) subjects discontinued study treatment in the CT-P17 and EU-

Table 1 Demographics and baseline disease characteristics (ITT population, unless otherwise specified)

\begin{tabular}{|c|c|c|}
\hline & CT-P17 $(N=324)$ & EU-adalimumab $(N=324)$ \\
\hline Age (years), median (range) & $53.5(18-75)$ & $54.0(19-75)$ \\
\hline \multicolumn{3}{|l|}{ Sex, $n(\%)$} \\
\hline Male & $75(23.1)$ & $59(18.2)$ \\
\hline Female & $249(76.9)$ & $265(81.8)$ \\
\hline \multicolumn{3}{|l|}{ Race, $n(\%)$} \\
\hline White & $299(92.3)$ & $298(92.0)$ \\
\hline Mestizo & $24(7.4)$ & $26(8.0)$ \\
\hline Native Peruvian & $1(0.3)$ & 0 \\
\hline \multicolumn{3}{|l|}{ Ethnicity, $n(\%)$} \\
\hline Hispanic or Latino & $29(9.0)$ & $34(10.5)$ \\
\hline Non-Hispanic or non-Latino & $295(91.0)$ & $290(89.5)$ \\
\hline RA disease duration (years), mean (SD) & $6.79(6.76)$ & $6.59(6.81)$ \\
\hline \multicolumn{3}{|l|}{ SDAl at screening, $n(\%)$} \\
\hline $\mathrm{SDAl} \leq 26$ & $30(9.3)$ & $34(10.5)$ \\
\hline SDAI > 26 & $294(90.7)$ & $290(89.5)$ \\
\hline SDAl, mean (SD) & $40.0(11.5)$ & $39.8(11.1)$ \\
\hline CDAl, mean (SD) & $39.0(11.0)$ & $38.7(10.8)$ \\
\hline DAS28-CRP, mean (SD) & $5.538(0.8738)$ & $5.547(0.8525)$ \\
\hline Tender joint count, mean (SD) & $20.5(10.2)$ & $20.1(10.1)$ \\
\hline Swollen joint count, mean (SD) & $14.0(6.33)$ & $14.0(6.46)$ \\
\hline Subject's assessment of pain, mean (SD) ${ }^{\mathrm{a}}$ & $69.7(18.7)$ & $70.0(16.2)$ \\
\hline Subject's global assessment of disease activity, mean (SD) ${ }^{a}$ & $69.8(17.8)$ & $69.6(16.3)$ \\
\hline Physician's global assessment of disease activity, mean (SD) ${ }^{a}$ & $67.5(14.7)$ & $67.0(15.5)$ \\
\hline HAQ estimate of physical ability, mean (SD) & $1.41(0.59)$ & $1.48(0.56)$ \\
\hline CRP $(\mathrm{mg} / \mathrm{dl})$, mean $(\mathrm{SD})$ & $0.975(1.60)$ & $1.10(1.91)$ \\
\hline $\mathrm{ESR}(\mathrm{mm} / \mathrm{h})$, mean $(\mathrm{SD})$ & $42.3(15.98)$ & $42.9(16.94)$ \\
\hline
\end{tabular}

Note: There were no significant differences between the CT-P17 and EU-adalimumab groups for any parameter $(p>0.05)$. For age (years), mean (SD) values were used for the statistical analysis

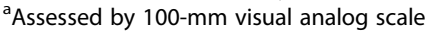

Anti-CCP anti-cyclic citrullinated peptide, CDAI Clinical Disease Activity Index, CRP C-reactive protein, DAS28 Disease Activity Score in 28 joints, ESR erythrocyte sedimentation rate, EU-adalimumab European Union-approved adalimumab, HAQ Health Assessment Questionnaire, ITT intention-to-treat, $R A$ rheumatoid arthritis, $R F$ rheumatoid factor, SD standard deviation, SDAI Simplified Disease Activity Index 
Table 2 EULAR (CRP) response rate and SDAl, CDAl, DAS28 (CRP), and Boolean remission rates up to week 24 (ITT population)

\begin{tabular}{|c|c|c|}
\hline & $\begin{array}{l}\text { CT-P17 }(N= \\
324)\end{array}$ & $\begin{array}{l}\text { EU-adalimumab }(N= \\
324)\end{array}$ \\
\hline \multicolumn{3}{|c|}{ EULAR (CRP) response, $n(\%)$} \\
\hline \multicolumn{3}{|l|}{ Week 2} \\
\hline Good response & $22(6.8)$ & $13(4.0)$ \\
\hline $\begin{array}{l}\text { Moderate } \\
\text { response }\end{array}$ & $154(47.5)$ & $139(42.9)$ \\
\hline \multicolumn{3}{|l|}{ Week 4} \\
\hline Good response & $72(22.2)$ & $68(21.0)$ \\
\hline $\begin{array}{l}\text { Moderate } \\
\text { response }\end{array}$ & $162(50.0)$ & $167(51.5)$ \\
\hline \multicolumn{3}{|l|}{ Week 8} \\
\hline Good response & $133(41.0)$ & $123(38.0)$ \\
\hline $\begin{array}{l}\text { Moderate } \\
\text { response }\end{array}$ & $143(44.1)$ & $144(44.4)$ \\
\hline \multicolumn{3}{|l|}{ Week 12} \\
\hline Good response & $162(50.0)$ & $165(50.9)$ \\
\hline $\begin{array}{l}\text { Moderate } \\
\text { response }\end{array}$ & $131(40.4)$ & $124(38.3)$ \\
\hline \multicolumn{3}{|l|}{ Week 16} \\
\hline Good response & $181(55.9)$ & $174(53.7)$ \\
\hline $\begin{array}{l}\text { Moderate } \\
\text { response }\end{array}$ & $112(34.6)$ & $109(33.6)$ \\
\hline \multicolumn{3}{|l|}{ Week 20} \\
\hline Good response & $202(62.3)$ & $201(62.0)$ \\
\hline $\begin{array}{l}\text { Moderate } \\
\text { response }\end{array}$ & $91(28.1)$ & $87(26.9)$ \\
\hline \multicolumn{3}{|l|}{ Week 24} \\
\hline Good response & $208(64.2)$ & $208(64.2)$ \\
\hline $\begin{array}{l}\text { Moderate } \\
\text { response }\end{array}$ & $86(26.5)$ & $81(25.0)$ \\
\hline \multicolumn{3}{|c|}{ CDAl remission rate, $n(\%)$} \\
\hline Week 2 & $2(0.6)$ & $2(0.6)$ \\
\hline Week 4 & $11(3.4)$ & $11(3.4)$ \\
\hline Week 8 & $21(6.5)$ & $24(7.4)$ \\
\hline Week 12 & $47(14.5)$ & $42(13.0)$ \\
\hline Week 16 & $51(15.7)$ & $63(19.4)$ \\
\hline Week 20 & $69(21.3)$ & $85(26.2)$ \\
\hline Week 24 & $82(25.3)$ & $86(26.5)$ \\
\hline \multicolumn{3}{|c|}{ SDAI remission rate, $n(\%)$} \\
\hline Week 2 & $2(0.6)$ & $2(0.6)$ \\
\hline Week 4 & $12(3.7)$ & $12(3.7)$ \\
\hline Week 8 & $22(6.8)$ & $22(6.8)$ \\
\hline Week 12 & $47(14.5)$ & 44 (13.6) \\
\hline Week 16 & $53(16.4)$ & 65 (20.1) \\
\hline Week 20 & $69(21.3)$ & 87 (26.9) \\
\hline
\end{tabular}

Table 2 EULAR (CRP) response rate and SDAI, CDAl, DAS28 (CRP), and Boolean remission rates up to week 24 (ITT population) (Continued)

\begin{tabular}{cll} 
& $\begin{array}{l}\text { CT-P17 (N= } \\
\text { 324) }\end{array}$ & $\begin{array}{l}\text { EU-adalimumab }(\boldsymbol{N}= \\
\mathbf{3 2 4})\end{array}$ \\
\hline Week 24 & $86(26.5)$ & $93(28.7)$ \\
DAS28 (CRP) remission rate, $n(\%)$ & \\
Week 2 & $11(3.4)$ & $10(3.1)$ \\
Week 4 & $32(9.9)$ & $38(11.7)$ \\
Week 8 & $67(20.7)$ & $68(21.0)$ \\
Week 12 & $109(33.6)$ & $107(33.0)$ \\
Week 16 & $128(39.5)$ & $118(36.4)$ \\
Week 20 & $150(46.3)$ & $146(45.1)$ \\
Week 24 & $158(48.8)$ & $157(48.5)$ \\
Boolean remission rate, & $n(\%)$ & \\
Week 2 & $2(0.6)$ & $2(0.6)$ \\
Week 4 & $9(2.8)$ & $10(3.1)$ \\
Week 8 & $17(5.2)$ & $17(5.2)$ \\
Week 12 & $32(9.9)$ & $33(10.2)$ \\
Week 16 & $40(12.3)$ & $56(17.3)$ \\
Week 20 & $56(17.3)$ & $66(20.4)$ \\
Week 24 & $58(17.9)$ & $68(21.0)$ \\
\hline
\end{tabular}

Note: There were no significant differences between the CT-P17 and EUadalimumab groups for any parameter $(p>0.05)$

CDAl Clinical Disease Activity Index, CRP C-reactive protein, DAS28 Disease

Activity Score in 28 joints, EU-adalimumab European Union-approved

adalimumab, EULAR European League Against Rheumatism, SDAI Simplified

Disease Activity Index

adalimumab groups, respectively. Withdrawal by subject was the most frequent reason for discontinuation (CTP17, 9 [2.8\%] subjects; EU-adalimumab, 7 [2.2\%] subjects), followed by TEAEs (CT-P17, 6 [1.9\%]; EUadalimumab, $7[2.2 \%])$. Of the $36(5.6 \%)$ subjects who discontinued study treatment, $25(3.9 \%)$ terminated the study (CT-P17, 15 [4.6\%]; EU-adalimumab, 10 [3.1\%]) and 11 (1.7\%) (CT-P17, 4 [1.2\%]; EU-adalimumab, 7 [2.2\%]) continued participation in the study.

Baseline demographics and disease characteristics were balanced between treatment groups (Table 1). Median age was 53.5 and 54.0 years for CT-P17 and EUadalimumab, respectively. Most subjects were female (CT-P17, 76.9\%; EU-adalimumab, 81.8\%) and were mainly enrolled by sites in Eastern European countries, particularly Poland (231 [71.3\%] subjects for both groups). Most subjects had high disease activity (SDAI score $>26$ ). Stratification factors, SDAI score category, and country were well balanced between groups.

\section{Efficacy}

Primary efficacy analysis

The ACR20 response rate at week 24 (Fig. 2a) was $82.7 \%$ ( $n=268 / 324)$ for both the CT-P17 and EU-adalimumab 
Table 3 Treatment-emergent adverse events (safety population)

\begin{tabular}{lll}
\hline & CT-P17 $(\boldsymbol{N}=\mathbf{3 2 4})$ & EU-adalimumab $(\mathbf{N}=\mathbf{3 2 4})$ \\
\hline Subjects with $\geq 1$ TEAE, $n(\%)$ & $169(52.2)$ & $184(56.8)$ \\
Study drug-related & $88(27.2)$ & $99(30.6)$ \\
TEAEs reported in $\geq 5 \%$ of subjects in either treatment group & & $22(6.8)$ \\
$\quad$ ISR & $16(4.9)$ & $20(6.2)$ \\
$\quad$ Nasopharyngitis & $17(5.2)$ & $20(6.2)$ \\
$\quad$ Upper respiratory tract infection & $17(5.2)$ & $17(5.2)$ \\
$\quad$ Neutropenia & $14(4.3)$ & $16(4.9)$ \\
Subjects with $\geq 1$ TESAE, $n$ (\%) & $10(3.1)$ & $8(2.5)$ \\
Subjects with $\geq 1$ TEAE leading to study drug discontinuation, $n(\%)$ & $5(1.5)$ & $4(1.2)$ \\
Subjects with $\geq 1$ TEAE classified as hypersensitivity/allergic reactions, $n(\%)$ & $2(0.6)$ & $22(6.8)$ \\
Subjects with $\geq 1$ TEAE classified as ISR, $n$ (\%) & $16(4.9)$ & $103(31.8)$ \\
Subjects with $\geq 1$ TEAE classified as infection, $n(\%)$ & $97(29.9)$ & 0 \\
Subjects with $\geq 1$ TEAE classified as malignancy, $n(\%)$ & $1(0.3)^{\mathrm{a}}$ & 0 \\
Total number of TEAEs leading to death & 0 &
\end{tabular}

Note: There were no significant differences between the CT-P17 and EU-adalimumab groups for any parameter $(p>0.05)$

a Breast cancer that was considered unrelated to study drug; the subject's family history of breast cancer was considered a risk factor by the investigator

TEAE treatment-emergent adverse event, EU-adalimumab European Union-approved adalimumab, ISR injection-site reaction, TESAE treatment-emergent serious adverse event

groups (ITT population). The $95 \%$ confidence interval (CI) of -5.94 to 5.94 for the estimate of treatment difference was entirely within the predefined equivalence margin of -15 to $15 \%$ (EMA assumption), demonstrating therapeutic equivalence between treatment groups. Results for the PP population supported those for the ITT population (CT-P17, 87.0\% [ $n=248 / 285]$; EUadalimumab, $87.0 \%[n=240 / 276])$, with the $95 \%$ CI of -5.60 to 5.78 for the estimate of treatment difference. Likewise, for both analysis populations, $90 \%$ CIs for the estimate of treatment difference $(-4.98$ to 4.98 in the ITT population and -4.70 to 4.86 in the PP population) were entirely within the asymmetric equivalence margin of -12 to $15 \%$ (FDA assumption), thereby also demonstrating therapeutic equivalence between treatment groups. Sensitivity analysis using logistic regression with covariates for the primary endpoint provided similar results, -5.75 to 5.86 (ITT population) and -5.07 to 5.93 (PP population) for $95 \% \mathrm{CI}$.

\section{Secondary and additional efficacy analyses}

The proportions of subjects achieving ACR20, ACR50, and ACR70 responses up to week 24 were similar between the CT-P17 and EU-adalimumab groups (Fig. 2a, b; Supplementary Table 3, Additional file 1). Mean values of and change from baseline in DAS28-CRP (Fig. 2c), CDAI (Fig. 2d), and SDAI (Fig. 2e) were comparable between groups up to week 24, as were EULAR (CRP) response rates and SDAI, CDAI, DAS28 (CRP), and Boolean remission rates (Table 2). Mean hybrid ACR scores increased from week 2 to week 24 and were similar between groups (Supplementary Table 3, Additional file 1). Mean SF-36 physical and mental component scores increased from baseline to week 24; mean increases up to week 24 were similar between groups. At week 24, mean (SD) change from baseline in the SF-36 physical component score was 7.869 (7.4184) for CTP17 $(n=309)$ and $8.213(8.0179)$ for EU-adalimumab $(n=312)$. At week 24 , mean (SD) change from baseline in the SF-36 mental component score was 5.879 (9.8480) for CT-P17 $(n=309)$ and 6.585 (9.7404) for EUadalimumab $(n=312)$.

\section{Pharmacokinetic analysis}

The mean adalimumab $C_{\text {trough }}$ was comparable between groups in the PK population, although values were slightly higher in the CT-P17 than in the EU-adalimumab group (Supplementary Table 4, Additional file 1). Mean $C_{\text {trough }}$ increased gradually from baseline to week 22 for both groups (Supplementary Figure 1, Additional file 1).

\section{Usability analysis}

Mean scores for each domain of the PRE-SIAQ and POST-SIAQ were comparable between treatment groups (Supplementary Table 5, Additional file 1). All subjects in the population in which usability was assessed completed self-injection successfully.

\section{Safety}

Overall, the proportion of subjects experiencing $\geq 1$ TEAE was similar between treatment groups (CT-P17, 169 [52.2\%] subjects; EU-adalimumab, 184 [56.8\%] 


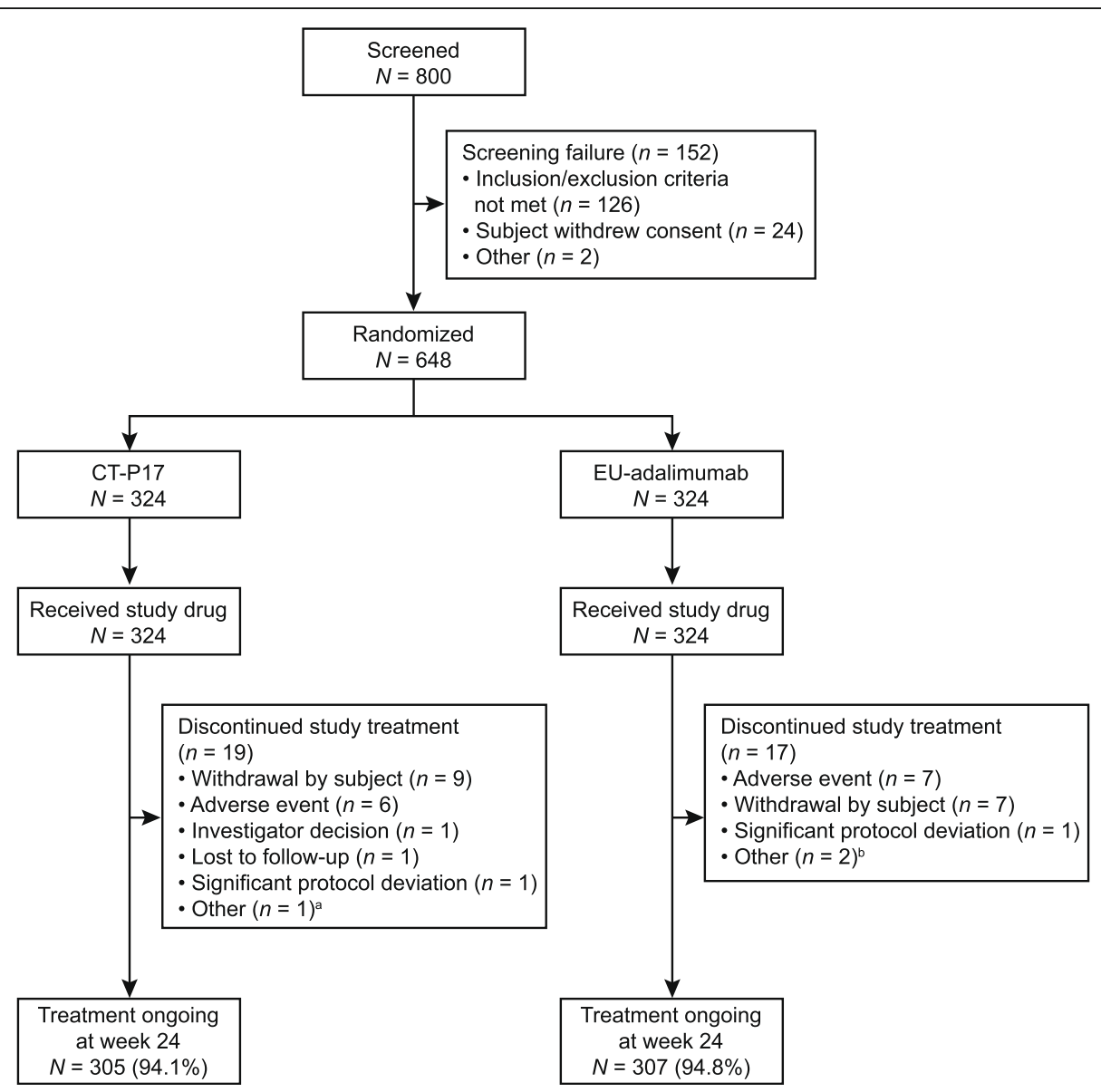

Fig. 1 Subject disposition (ITT population). ${ }^{a}$ Subject discontinued CT-P17 treatment due to significant dose delay due to adverse event. ${ }^{\text {bTwo }}$ subjects discontinued EU-adalimumab treatment due to subject decision due to adverse event. EU-adalimumab, European Union-approved adalimumab; ITT, intention-to-treat

subjects) (Table 3). Most TEAEs were grade 1 or 2 in intensity. TEAEs considered by the investigator to be study drug-related were reported by 187 (28.9\%) subjects, with similar proportions between treatment groups (CT-P17, 88 [27.2\%]; EU-adalimumab, 99 [30.6\%]) (Table 3). A similar proportion of subjects in each group experienced TEAEs leading to study drug discontinuation; of these, 2 $(0.6 \%)$ and $4(1.2 \%)$ subjects, respectively, experienced TEAEs that were considered study drug related. The most frequently reported TEAEs in the CT-P17 group were nasopharyngitis and upper respiratory tract infection (17 [5.2\%] subjects each) and ISR (16 [4.9\%]); in the EU-adalimumab group, these were ISR $(22[6.8 \%])$ and nasopharyngitis and upper respiratory tract infection (20 [6.2\%] each) (Table 3). Treatment-emergent serious adverse events (TESAEs) were reported for 10 (3.1\%) subjects in the CT-P17 group and 16 (4.9\%) in the EUadalimumab group (Table 3). Study drug-related TESA Es were reported for 9 subjects overall (CT-P17, 5 [1.5\%]; EU-adalimumab, 4 [1.2\%]) (Supplementary
Table 6, Additional file 1). No deaths were reported up to week 24.

TEAEs classified as hypersensitivity/allergic reactions, ISRs, or infections were experienced by similar proportions of subjects in each group (Table 3). Conversion to positive interferon- $\gamma$ release assay, up to week 24 , was experienced by $12(3.7 \%)$ and $17(5.2 \%)$ subjects in the CT-P17 and EU-adalimumab groups, respectively. Latent tuberculosis was reported in $12(3.7 \%)$ and $15(4.6 \%)$ subjects in the CT-P17 and EU-adalimumab groups, respectively; for $7(2.2 \%)$ and $10(3.1 \%)$ of these subjects, this was considered study drug-related. All these subjects began tuberculosis prophylaxis, except for the single subject in each group who terminated study participation. Two $(0.6 \%)$ subjects in the EU-adalimumab group reported active tuberculosis and discontinued study treatment. One $(0.3 \%)$ subject experienced a TEAE classified as malignancy (breast cancer) in the CT-P17 group (Table 3); however, the site investigator considered this event to be unrelated to study drug. 
$\sim \mathrm{CT}-\mathrm{P} 17(N=324) \quad \sim$ EU-adalimumab $(N=324)$
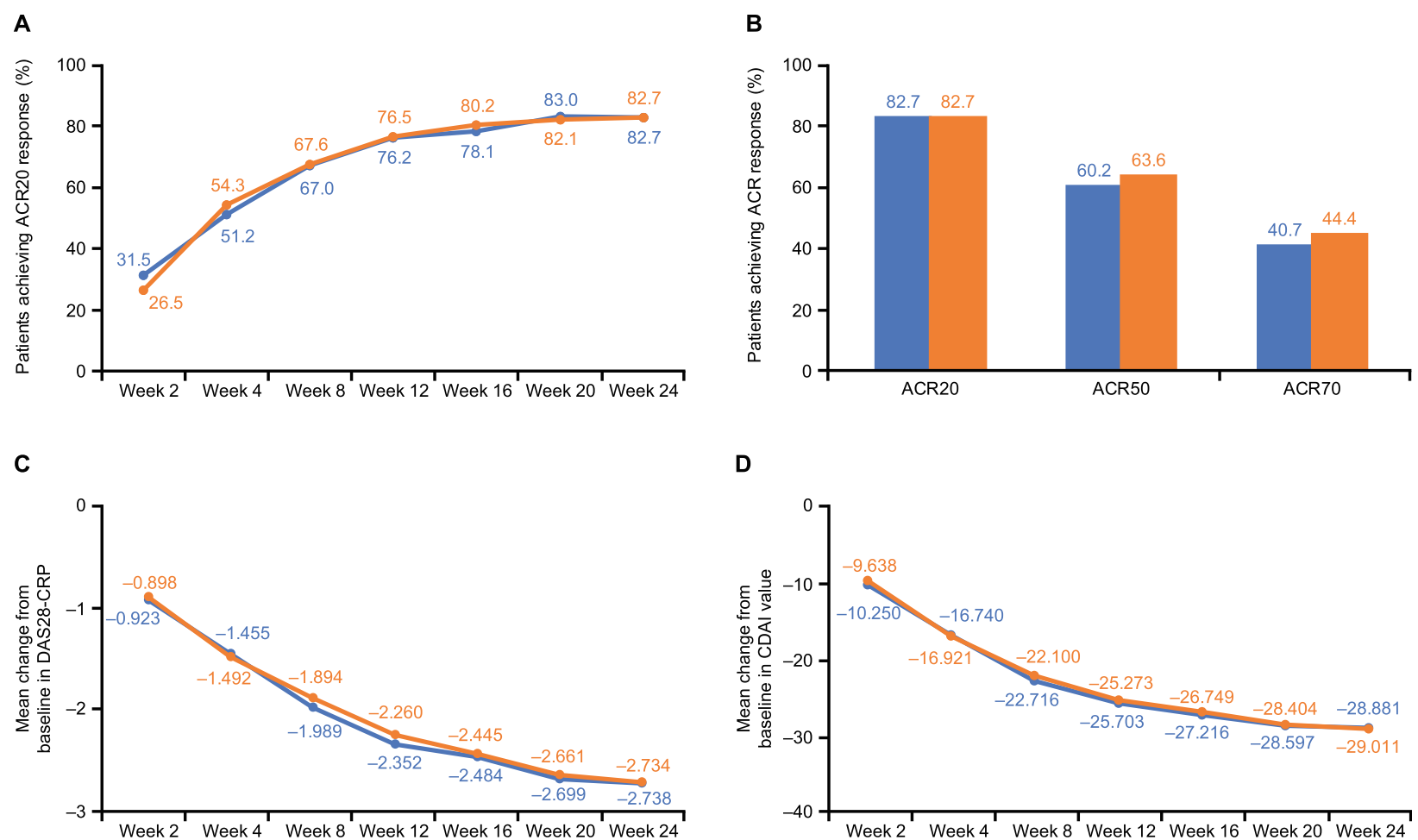

D

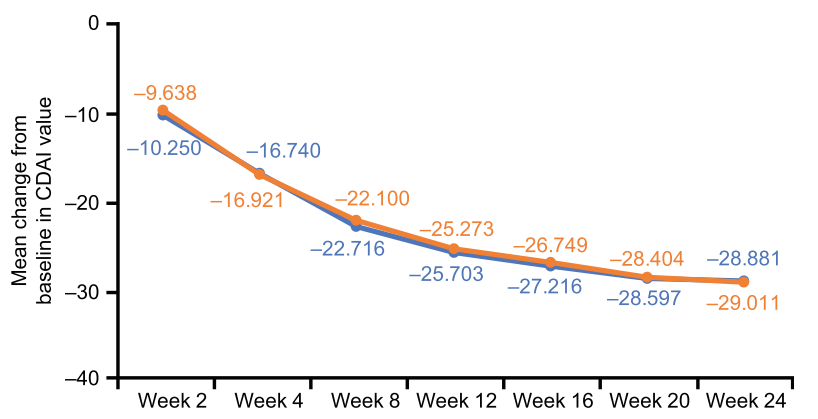

$\mathbf{E}$

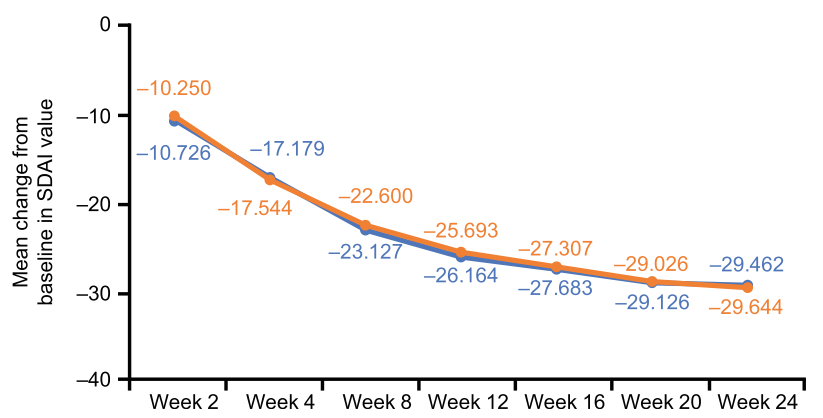

Fig. 2 Secondary efficacy endpoints up to week 24 (ITT population). ACR20 response rate up to week 24 (a). ACR20, ACR50, and ACR70 response rates at week 24 (b). Mean change from baseline in DAS28-CRP up to week 24 (c). Mean change from baseline in CDAl value up to week 24 (d). Mean change from baseline in SDAI value up to week 24 (e). ACR, American College of Rheumatology; ACR20, 20\% improvement according to American College of Rheumatology criteria; ACR50, 50\% improvement according to American College of Rheumatology criteria; ACR70, 70\% improvement according to American College of Rheumatology criteria; CDAl, Clinical Disease Activity Index; DAS28-CRP, Disease Activity Score in 28 joints C-reactive protein; EU-adalimumab, European Union-approved adalimumab; ITT, intention-to-treat; SDAl, Simplified Disease Activity Index

Small imbalances were identified in the proportions of subjects reporting TEAEs classified in the SOC of gastrointestinal disorders (CT-P17, 24 [7.4\%] subjects; EU-adalimumab, 16 [4.9\%] subjects), nervous system disorders (CT-P17, 19 [5.9\%] subjects; EU-adalimumab, 9 [2.8\%] subjects), and metabolism and nutrition disorders (CT-P17, 12 [3.7\%] subjects; EU-adalimumab, 6 [1.9\%] subjects) (Supplementary Table 7, Additional file 1). However, among these SOCs, other than for two grade 3
TEAEs that were considered unrelated to study drug in the EU-adalimumab group (1 nervous system disorder of carotid arteriosclerosis, and 1 metabolism and nutrition disorder of hypertriglyceridemia), all TEAEs were grade $1-2$ in intensity.

Mean (SD) 100-mm VAS scores for local site pain measurements decreased over time. Results at each visit were comparable between treatment groups. At week 0 , mean (SD) VAS scores for local site pain were 6.64 
(10.887) for CT-P17 and 4.85 (7.300) for EUadalimumab, while mean VAS scores at week 24 had decreased to 4.45 (8.393) for CT-P17 and to 4.32 (8.651) for EU-adalimumab.

\section{Immunogenicity}

At baseline, $11(3.4 \%)$ and $6(1.9 \%)$ subjects were ADApositive and $4(1.2 \%)$ and $1(0.3 \%)$ subjects were NAbpositive in the CT-P17 and EU-adalimumab groups, respectively (Supplementary Table 8 , Additional file 1). At week 24, $93(28.7 \%)$ and $116(35.8 \%)$ subjects were ADA-positive and $83(25.6 \%)$ and $103(31.8 \%)$ subjects were NAb-positive in the CT-P17 and EU-adalimumab groups, respectively. Overall, immunogenicity was slightly lower numerically for the CT-P17 group than for the EU-adalimumab group throughout the study.

\section{ADA subgroup analysis}

The proportions of subjects achieving an ACR20 response at week 24 were similar between the CT-P17 and the EU-adalimumab treatment groups in both the ADApositive and ADA-negative subgroups (Supplementary Table 9, Additional file 1). Mean $C_{\text {trough }}$ was lower in the ADA-positive subgroup than in the ADA-negative subgroup for both treatment groups (Supplementary Figure 1 and Supplementary Table 4, Additional file 1). A lower proportion of subjects in the ADA-negative subgroup experienced $\geq 1$ TEAE than did those in the ADApositive subgroup ( $49.7 \%$ and $59.8 \%$, respectively); however, with a limited number of events, there was no apparent correlation between the presence of ADA and the incidence of TESAEs, TEAEs classified as hypersensitivity/reactions, or TEAEs classified as ISRs (Supplementary Table 10, Additional file 1).

\section{Discussion}

This study demonstrated equivalent efficacy of CT-P17 to EU-adalimumab in the proportion of subjects achieving an ACR20 response at week 24. This primary endpoint was met in both the ITT and PP analysis populations for both the EMA ( -15 to $15 \%, 95 \% \mathrm{CI}$ ) and the FDA ( -12 to $15 \%, 90 \% \mathrm{CI}$ ) statistical assumptions. Comparable efficacy of CT-P17 and EUadalimumab was demonstrated for secondary endpoints up to week 24. PK parameters were also comparable between groups, although mean $C_{\text {trough }}$ was slightly higher for CT-P17 than for EU-adalimumab. The usability of CT-P17, assessed by ability to complete successful selfinjections and subject-reported outcomes, was comparable to that of EU-adalimumab. The overall safety profile of CT-P17 was similar to that of EU-adalimumab, although there were small imbalances between the CTP17 and EU-adalimumab groups for some SOCs.
In our study, the ACR20 response rate at week 24, using high-concentration $(100 \mathrm{mg} / \mathrm{ml})$ formulations of CT-P17 and EU-adalimumab, was $82.7 \%$ in both treatment groups (ITT population). These observed ACR20 response rates are only slightly above the range of ACR20 responses for reference adalimumab $(50 \mathrm{mg} / \mathrm{ml})$ and adalimumab biosimilars in other adalimumab biosimilar studies, in which ACR20 response rates at week 24 or week 26 ranged between 63.9 and 82.5\% (Supplementary Figure 2, Additional file 1) [21-25]. However, our study did not compare the high-concentration formulation to the low-concentration formulation of adalimumab.

We also investigated the influence of immunogenicity status on the proportion of subjects achieving an ACR20 response at week 24 . Overall, a slightly lower proportion of ADA-positive subjects achieved an ACR20 response at week 24 than did ADA-negative subjects $(81.4 \%$ vs $85.1 \%)$, consistent with previous reports for reference adalimumab and adalimumab biosimilars [13, 26]. However, within subject subgroups by ADA status, ACR20 response rates were similar between CT-P17 and EUadalimumab treatment groups, in line with similar data reported previously for adalimumab biosimilars [26, 27].

In this study, we observed slightly higher mean $C_{\text {trough }}$ values in the CT-P17 group compared with the EUadalimumab group. In a separate study, ADA formation was associated with increased clearance and lower serum adalimumab concentrations [13]. However, in this study, AUC and clearance were not evaluated, so this could not be examined directly. It is possible that the differences may be associated with the lower proportion of ADApositive subjects in the CT-P17 versus EU-adalimumab group. Indeed, in our study, $C_{\text {trough }}$ was generally lower in the ADA-positive than in the ADA-negative subgroup; $C_{\text {trough }}$ values became more similar between groups when compared within these subgroups. Nevertheless, $C_{\text {trough }}$ values of the ADA-positive subgroup were within the therapeutic level of adalimumab (5 to $8 \mu \mathrm{g} / \mathrm{ml}$ ) [13]. In addition, our findings are in keeping with previous reports for adalimumab biosimilars $[26,28]$.

The overall safety profile of CT-P17 in this study was consistent with the known safety profile of reference adalimumab [13]. In both treatment groups, the most frequently reported study drug-related TEAEs were ISRs, consistent with information provided in the EUadalimumab summary of product characteristics [13]. ISRs, as well as the other protocol-specified TEAESIs of hypersensitivity/allergic reactions and infections, were experienced by similar proportions of subjects in each treatment group. There were small imbalances, at the SOC level, in the proportions of subjects reporting TEAEs for gastrointestinal disorders, nervous system 
disorders, and metabolism and nutrition disorders. These TEAEs were mostly grade $1-2$ in intensity and, at the Preferred Term level, absolute differences between groups in the number of subjects experiencing a given TEAE were small. When analyzed by ADA status, the incidence of TEAEs, but not of TESAEs, was higher for ADA-positive than for ADA-negative subjects; there was no apparent correlation between the presence of ADAs and hypersensitivity/allergic reactions or ISRs.

This is the first report of a phase III clinical trial comparing CT-P17 to reference adalimumab. Strengths of this study include its randomized, double-blind design, and the use of well-established outcome measures. Equivalent efficacy of CT-P17 and EU-adalimumab was established using both symmetric and asymmetric equivalence margins, as agreed to by the EMA and the FDA, respectively. In addition to the data reported from comparing these treatments up to week 24, this study will provide valuable information regarding the efficacy and safety of transitioning from EU-adalimumab to CTP17 (during treatment period 2).

Limitations of this study include the relatively short follow-up period (24 weeks) reported herein; however, this study is ongoing and efficacy and safety data up to week 52 will be reported. Although sufficient testing was done for regulatory purposes, comprehensive PK data were not collected. While treatment groups were well balanced by stratification factors including country, subjects from Eastern European countries, particularly Poland, accounted for most of the study population. The races of subjects enrolled in this study included white, mestizo, and Native Peruvian. This could limit the global generalizability of the findings; however, this should be viewed in the context of the global scope of the CT-P17 clinical development program that included American Indian or Alaska Native, Black or African American, and Asian subjects, among which there were no differences in clinical responses [11, 16, 29]. Also, since this was a comparative study to demonstrate equivalence of CTP17 to EU-adalimumab, it did not aim to evaluate the drugs across other ethnic groups.

The original reference adalimumab was developed as a low-concentration $(50 \mathrm{mg} / \mathrm{ml})$ formulation containing citrate. Subsequently, a high-concentration $(100 \mathrm{mg} / \mathrm{ml})$, citrate-free formulation of reference adalimumab has been developed $[13,14]$. While the high-concentration CT-P17 formulation is similar to the newer formulation of reference adalimumab [13, 14], it differs from the low-concentration $(50 \mathrm{mg} / \mathrm{ml})$ adalimumab biosimilars that are currently approved [12, 30-33]. The highconcentration formulations of both CT-P17 and reference adalimumab offer the potential to administer highdose $(80 \mathrm{mg} / 0.8 \mathrm{ml})$ induction treatment to patients with inflammatory bowel disease with a reduced number of injections. In addition, the citrate-free buffer may benefit patients by reducing discomfort during injection [12, $15]$.

\section{Conclusions}

In conclusion, demonstration of equivalent efficacy and comparable safety and immunogenicity of CT-P17 to EU-adalimumab in this study support the ongoing clinical evaluation of CT-P17 as an adalimumab biosimilar.

\section{Supplementary Information}

Supplementary information accompanies this paper at https://doi.org/10. 1186/s13075-020-02394-7.

Additional file 1: Supplementary methods, including Table S1 Study centers and IRB/IEC information, Full inclusion and exclusion criteria, Table S2 Schedule of assessments (screening and treatment period 1), and Analysis populations. Table S3 ACR50 and ACR70 response rates and hybrid ACR scores up to week 24 (ITT population). Table S4 Mean (SD) $C_{\text {trough }}$ overall and by ADA status (PK population). Figure $\mathbf{S 1}$ Mean ( \pm SD) $C_{\text {trough }}$ by ADA status (PK population). Table S5 Mean (SD) scores by domain for PRE-SIAQ and POST-SIAQ (usability population). Table S6 Study drug-related TESAEs (safety population). Table S7 TEAEs by System Organ Class reported by $\geq 2 \%$ of subjects in either treatment group (safety population). Table $\mathbf{S 8}$ Summary of immunogenicity results (safety population). Table S9 ACR20 response rate at week 24 by ADA status (ITT population). Table S10 Treatment-emergent adverse events by ADA status (safety population). Figure S2 Historical data for ACR20 response rate at week 24 for reference or biosimilar adalimumab $(50 \mathrm{mg} / \mathrm{ml})$, compared with CT-P17 or reference adalimumab $(100 \mathrm{mg} / \mathrm{ml})$ treatment in the current study (ITT population).

\section{Abbreviations}

ACR: American College of Rheumatology; ACR20: 20\% improvement according to American College of Rheumatology criteria; ADA: Anti-drug antibody; bDMARD: Biological disease-modifying antirheumatic drug; bsDMARD: Biosimilar disease-modifying antirheumatic drug; CDAl: Clinical Disease Activity Index; Cl: Confidence interval; CRO: Contract Research Organization; CRP: C-reactive protein; CSDMARD: Conventional synthetic disease-modifying antirheumatic drug; $C_{\text {trough: }}$ Trough serum adalimumab concentration; DAS28: Disease Activity Score in 28 joints; EMA: European Medicines Agency; EU-adalimumab: European Union-approved adalimumab; EULAR: European League Against Rheumatism; ESR: Erythrocyte sedimentation rate; FDA: US Food and Drug Administration; ISR: Injection-site reaction; ITT: Intention-to-treat; IWRS: Interactive web response system; NAb: Neutralizing antibody; PK: Pharmacokinetics; PP: Per-protocol; q2w: Every 2 weeks; SDAl: Simplified Disease Activity Index; SF-36: 36-item Short Form Health Survey; SIAQ: Self-Injection Assessment Questionnaire; SOC: System Organ Class; TEAE: Treatment-emergent adverse event; TEAE SI: Treatment-emergent adverse event of special interest; TESAE: Treatmentemergent serious adverse event; TNF: Tumor necrosis factor; VAS: Visual analog scale

\section{Acknowledgements}

We thank all study investigators, staff, and subjects who contributed to this study. The study was sponsored by Celltrion, Inc. (Incheon, Republic of Korea). Medical writing support (including development of a draft outline and subsequent drafts in consultation with the authors, assembling tables and figures, collating author comments, copyediting, fact checking, and referencing) was provided by Emma Evans, PhD CMPP, and Beatrice Tyrrell, DPhil, at Aspire Scientific Limited (Bollington, UK), and funded by Celltrion, Inc. (Incheon, Republic of Korea).

\section{Authors' contributions}

$J K, D E F$, and EK made substantial contributions to the conception and design of the work and the interpretation of data. JJ, RW, PW, AD, MK, SJ, AZ, JT, KB-M, MK-W, and PAK made substantial contributions to the acquisition 
and interpretation of data. SJL, YJB, GEY, and JKY made substantial contributions to the conception and design of the work and the analysis and interpretation of data. All authors contributed to drafting the work or substantially revising it and have approved the final manuscript.

\section{Funding}

This study was funded by Celltrion, Inc. (Incheon, Republic of Korea).

\section{Availability of data and materials}

Available data and methodological information for this ongoing study are included in this article and accompanying supplementary materials.

\section{Ethics approval and consent to participate}

The study was performed in accordance with the Declaration of Helsinki and Good Clinical Practice guidelines. All national, state, and local laws or regulations were followed. Before study initiation, the study protocol was reviewed and approved by the independent ethics committee/institutional review board at each site (Supplementary Table 1, Additional file 1). All subjects provided written informed consent.

\section{Consent for publication}

Not applicable.

\section{Competing interests}

JK has received consultancies, speaking fees, and/or honoraria from AbbVie; Alvotech Suisse AG; Boehringer Ingelheim GmbH; Celltrion Healthcare Co. Ltd.; Merck \& Co., Inc.; Mylan Inc.; Novartis AG; Samsung Bioepis; Sandoz; and UCB. JJ, RW, PW, AD, and MK have received investigator fees from Celltrion, Inc. SJ has received speaking fees from AbbVie, Egis, Eli Lilly, MSD, Novartis, Pfizer, Roche, Sandoz, and UCB; and investigator fees from Celltrion, Inc. AZ, JT, KB-M, MK-W, and PAK have received investigator fees from Celltrion, Inc. SJL, YJB, GEY, and JKY are employed by Celltrion, Inc. DEF has received grant/research support from Corbus, CSL Behring, Galapagos, Gilead, GSK, Kadmon, PICORI, Pfizer, and Talaris; and consultancies from AbbVie, Amgen, Boehringer Ingelheim, Corbus, CSL Behring, Galapagos, Gilead, Novartis, Pfizer, Roche/Genentech, and Talaris. EK has received consultancies from AbbVie, Amgen, Celltrion, Gilead, Janssen, Lilly, Merck, Pfizer, Roche, Samsung Bioepis, Sandoz, and Sanofi; and speaker honoraria from AbbVie, Amgen, Gilead, Janssen, Lilly, Merck, Pfizer, Roche, Sandoz, and Sanofi.

\section{Author details}

'University of Massachusetts Medical School and UMass Memorial Medical, Worcester, MA, USA. ${ }^{2}$ Reumatika-Centrum Reumatologii, Warsaw, Poland. ${ }^{3}$ University Hospital No 2, Bydgoszcz, Poland. ${ }^{4}$ Medical University, Wroclaw, Poland. ${ }^{5}$ Centrum Medyczne AMED, Warsaw, Poland. ${ }^{6}$ Rheumatology Clinic NZOZ Lecznica MAK-MED, Nadarzyn, Poland. ${ }^{7}$ Nasz Lekarz Przychodnie Medyczne, Toruń, Poland. ${ }^{8}$ Medycyna Kliniczna Marzena Waszczak-Jeka, Warsaw, Poland. ${ }^{9}$ Reuma Centrum, Warsaw, Poland. ${ }^{10}$ Centrum Medyczne AMED Oddzial w Lodzi, Łódź, Poland. ${ }^{11}$ University of Warmia and Mazury, Olsztyn, Poland. ${ }^{12}$ Medical University of Bialystok and Gabinet Internistyczno-Reumatologiczny Piotr Adrian Klimiuk, Białystok, Poland. ${ }^{13}$ Celltrion, Inc., Incheon, Republic of Korea. ${ }^{14}$ University of California, Los Angeles, CA, USA. ${ }^{15}$ University of Washington, Seattle, WA, USA. ${ }^{16}$ University of Florence, Florence, Italy. ${ }^{1}$ University of Toronto, Toronto, Canada.

Received: 23 September 2020 Accepted: 13 December 2020 Published online: 05 February 2021

\section{References}

1. Singh JA, Saag KG, Bridges SL Jr, Akl EA, Bannuru RR, Sullivan MC, et al. 2015 American College of Rheumatology guideline for the treatment of rheumatoid arthritis. Arthritis Rheumatol. 2016;68(1):1-26.

2. Furst $D E$, Schiff MH, Fleischmann RM, Strand V, Birbara CA, Compagnone D, et al. Adalimumab, a fully human anti tumor necrosis factor-alpha monoclonal antibody, and concomitant standard antirheumatic therapy for the treatment of rheumatoid arthritis: results of STAR (Safety Trial of Adalimumab in Rheumatoid Arthritis). J Rheumatol. 2003;30(12):2563-71.

3. Keystone EC, Kavanaugh AF, Sharp JT, Tannenbaum H, Hua Y, Teoh LS, et al. Radiographic, clinical, and functional outcomes of treatment with adalimumab (a human anti-tumor necrosis factor monoclonal antibody) in patients with active rheumatoid arthritis receiving concomitant methotrexate therapy: a randomized, placebo-controlled, 52-week trial. Arthritis Rheum. 2004;50(5):1400-11.

4. van de Putte LBA, Atkins C, Malaise M, Sany J, Russell AS, van Riel PLCM, et al. Efficacy and safety of adalimumab as monotherapy in patients with rheumatoid arthritis for whom previous disease modifying antirheumatic drug treatment has failed. Ann Rheum Dis. 2004;63(5):508.

5. Weinblatt ME, Keystone EC, Furst DE, Moreland LW, Weisman MH, Birbara CA, et al. Adalimumab, a fully human anti-tumor necrosis factor a monoclonal antibody, for the treatment of rheumatoid arthritis in patients taking concomitant methotrexate: the ARMADA trial. Arthritis Rheum. 2003; 48(1):35-45.

6. European Medicines Agency. Guideline on similar biological medicinal products containing biotechnology-derived proteins as active substance: non-clinical and clinical issues. Available from: https://www.ema.europa.eu/ en/documents/scientific-guideline/guideline-similar-biological-medicinalproducts-containing-biotechnology-derived-proteins-active_en-2.pdf. [cited 3 Apr 2020].

7. The Center for Biosimilars. Pfizer's biosimilar adalimumab receives positive CHMP opinion. Available from: https://www.centerforbiosimilars.com/news/ pfizers-biosimilar-adalimumab-receives-positive-chmp-opinion. [cited 11 Mar 2020].

8. Generics and Biosimilars Initiative. Biosimilars of adalimumab. Available from http://www.gabionline.net/Biosimilars/General/Biosimilars-of-adalimumab. [cited 11 Mar 2020].

9. Smolen JS, Landewé R, Bijlsma J, Burmester G, Chatzidionysiou K, Dougados $M$, et al. EULAR recommendations for the management of rheumatoid arthritis with synthetic and biological disease-modifying antirheumatic drugs: 2016 update. Ann Rheum Dis. 2017;76(6):960.

10. ClinicalTrials.gov. A study to compare efficacy and safety of CT-P17 with Humira in patients with active rheumatoid arthritis (NCT03789292). Available from: https://clinicaltrials.gov/ct2/show/NCT03789292. [cited 21 Mar 2020].

11. ClinicalTrials.gov. To compare the pharmacokinetics and safety of CT-P17 and Humira in healthy subjects (NCT03970824). Available from: https:// clinicaltrials.gov/ct2/show/NCT03970824. [cited 7 Apr 2020].

12. Davio K. Celltrion completes enrollment of phase 3 trial of CT-P17, gives update on subcutaneous CT-P13. Available from: https://www. centerforbiosimilars.com/news/celltrion-completes-enrollment-of-phase-3trial-of-ctp17-gives-update-on-subcutaneous-ctp13. [cited 11 Mar 2020].

13. European Medicines Agency. Humira summary of product characteristics. Available from: https://www.ema.europa.eu/en/documents/productinformation/humira-epar-product-information_en.pdf. [cited 12 Mar 2020].

14. US Food and Drug Administration. Humira prescribing information. Available from: https://www.accessdata.fda.gov/drugsatfda_docs/label/201 9/125057Orig1s411lbl.pdf. [cited 12 Mar 2020].

15. Nash P, Vanhoof J, Hall S, Arulmani U, Tarzynski-Potempa R, Unnebrink K, et al. Randomized crossover comparison of injection site pain with $40 \mathrm{mg} / 0.4$ or $0.8 \mathrm{~mL}$ formulations of adalimumab in patients with rheumatoid arthritis. Rheumatol Ther. 2016;3(2):257-70.

16. ClinicalTrials.gov. To compare the pharmacokinetics and safety of the autoinjector and pre-filled syringe of CT-P17 (NCT04295356). Available from: https://clinicaltrials.gov/ct2/show/NCT04295356. [cited 12 Mar 2020].

17. World Medical Association Declaration of Helsinki: ethical principles for medical research involving human subjects. JAMA. 2013;310(20):2191-4.

18. International Conference on Harmonisation (ICH). Tripartite guideline. Guidance for good clinical practice E6 (R1). Available from: https://www. ema.europa.eu/en/documents/scientific-guideline/ich-e6-r1-guideline-goodclinical-practice_en.pdf. [cited 6 Mar 2020].

19. Aletaha D, Neogi T, Silman AJ, Funovits J, Felson DT, Bingham CO 3rd, et al. 2010 rheumatoid arthritis classification criteria: an American College of Rheumatology/European League Against Rheumatism collaborative initiative. Ann Rheum Dis. 2010;69(9):1580-8.

20. Chan ISF, Zhang Z. Test-based exact confidence intervals for the difference of two binomial proportions. Biometrics. 1999;55(4):1202-9.

21. US Food and Drug Administration Center for Drug Evaluation and Research. Statistical review and evaluation: ABP 501. Available from: https:/www. accessdata.fda.gov/drugsatfda_docs/nda/2016/761024Orig1 s000StatR.pdf. [cited 7 Jul 2020].

22. US Food and Drug Administration Center for Drug Evaluation and Research. Biosimilar multi-disciplinary evaluation and review: SB5. Available from: https://www.accessdata.fda.gov/drugsatfda_docs/nda/2019/761059Orig1 s000MultidisciplineR.pdf. [cited 7 Jul 2020]. 
23. US Food and Drug Administration Center for Drug Evaluation and Research. Statistical review and evaluation: Bl 695501. Available from: https://www. accessdata.fda.gov/drugsatfda_docs/nda/2017/761058Orig1s000StatR.pdf. [cited 7 Jul 2020].

24. European Medicines Agency. Assessment report: Hulio. Available from: https://www.ema.europa.eu/en/documents/assessment-report/hulio-eparpublic-assessment-report_en.pdf. [cited 7 Jul 2020].

25. US Food and Drug Administration Center for Drug Evaluation and Research Biosimilar multi-disciplinary evaluation and review: PF-06410293. Available from: https://www.accessdata.fda.gov/drugsatfda_docs/nda/2019/76111 8Orig1 15000MultidisciplineR.pdf. [cited May 28 2020].

26. Weinblatt ME, Baranauskaite A, Niebrzydowski J, Dokoupilova E, Zielinska A, Jaworski J, et al. Phase III randomized study of SB5, an adalimumab biosimilar, versus reference adalimumab in patients with moderate-tosevere rheumatoid arthritis. Arthritis Rheumatol. 2018:70(1):40-8.

27. Cohen S, Genovese MC, Choy E, Perez-Ruiz F, Matsumoto A, Pavelka K, et al. Efficacy and safety of the biosimilar ABP 501 compared with adalimumab in patients with moderate to severe rheumatoid arthritis: a randomised, doubleblind, phase III equivalence study. Ann Rheum Dis. 2017;76(10):1679-87.

28. Cohen SB, Alonso-Ruiz A, Klimiuk PA, Lee EC, Peter N, Sonderegger I, et al. Similar efficacy, safety and immunogenicity of adalimumab biosimilar Bl 695501 and Humira reference product in patients with moderately to severely active rheumatoid arthritis: results from the phase III randomised VOLTAIRE-RA equivalence study. Ann Rheum Dis. 2018;77(6):914-21.

29. ClinicalTrials.gov. A study to evaluate usability of subcutaneous auto-injector of CT-P17 in patients with active rheumatoid arthritis (NCT04171414). Available from: https://clinicaltrials.gov/ct2/show/NCT04171414. [cited 7 Apr 2020].

30. European Medicines Agency. Amgetiva summary of product characteristics. Available from: https:/www.ema.europa.eu/en/documents/productinformation/amgevita-epar-product-information_en.pdf. [cited 7 Apr 2020].

31. European Medicines Agency. Hulio summary of product characteristics. Available from: https://www.ema.europa.eu/en/documents/productinformation/hulio-epar-product-information_en.pdf. [cited 7 Apr 2020].

32. US Food and Drug Administration. Abrilada prescribing information. Available from: https://www.accessdata.fda.gov/drugsatfda_docs/label/2019/ 761118s000lbl.pdf. [cited 11 Mar 2020].

33. US Food and Drug Administration. Cyltezo prescribing information. Available from: https://www.accessdata.fda.gov/drugsatfda_docs/label/2019/ 761058s003lbl.pdf. [cited 7 Apr 2020].

\section{Publisher's Note}

Springer Nature remains neutral with regard to jurisdictional claims in published maps and institutional affiliations.

Ready to submit your research? Choose BMC and benefit from:

- fast, convenient online submission

- thorough peer review by experienced researchers in your field

- rapid publication on acceptance

- support for research data, including large and complex data types

- gold Open Access which fosters wider collaboration and increased citations

- maximum visibility for your research: over $100 \mathrm{M}$ website views per year

At $\mathrm{BMC}$, research is always in progress.

Learn more biomedcentral.com/submissions 